\title{
Estudo sobre o uso de resíduos queratinosos como biofertilizante
}

Atualmente, observa-se um aumento expressivo no número de animais de estimação nas famílias e esse fato tem demandado maiores cuidados com esses animais, acarretando no aumento das atividades dos pet shops, que oferecem entre seus serviços, os cuidados com higiene, como a tosa, contudo, este procedimento gera grande quantidade de pelos. Os pelos são classificados como resíduos queratinosos e podem, quando descartados de forma incorreta, poluir o meio ambiente. Por isso, pesquisadores investigam formas de destinação destes resíduos como compor rações animais ou seu uso como biofertilizante. Desta forma, o objetivo desse trabalho foi avaliar o uso de substratos elaborados com diferentes quantidades de pelos de cães e em diferentes tempos de degradação no cultivo de alface americana. $O$ experimento foi implantado em um delineamento inteiramente casualizado, em esquema fatorial $3 \times 3$ ( 3 composições de substratos $x$ três tempos de decomposição do pelo de cão), com 10 repetições por tratamento, onde cada repetição foi constituída por uma unidade de $1 \mathrm{~kg}$ contendo uma planta de alface americana cultivar Grandes Lagos, totalizando 90 unidades experimentais. A composição dos substratos empregados foi: substrato composto por $80 \%$ de solo + $20 \%$ de pelo, $90 \%$ de solo $+10 \%$ de pelo e testemunha, contendo $100 \%$ de solo, e o tempo de degradação foi de 90,120 e 150 dias. Foram avaliados o número de folhas, o diâmetro da parte aérea, a altura da parte aérea, a massa fresca da parte aérea, o comprimento de raiz e a massa fresca da raiz. 0 uso de substratos contendo pelos de cachorros incorporados em diferentes quantidades e com tempos diferentes de degradação prejudicou $(p<0,05)$ o desempenho agronômico da alface americana, a massa fresca da parte aérea e o comprimento e a massa fresca da raiz. Sugere-se que mais pesquisas sejam conduzidas, pautadas em maior tempo de degradação e/ou o uso de técnicas de hidrólise prévia da queratina presente no pelo, a fim de viabilizar o uso desse resíduo como biofertilizante.

Palavras-chave: Cultivo de alface; Gestão de resíduos; Pelo de cachorro.

\section{Study on the use of keratin waste as a biofertilizer}

The number of pet shops has increased due to the greater number of pets, mainly dogs, which require hygiene care such as grooming, however, this procedure generates a large amount of dog fur. Dog fur is classified as keratinous waste and can, when improperly disposed of, pollute the environment. For this reason, researchers are investigating ways to dispose of these residues as animal feed or their use as biofertilizer in order to reduce their environmental impact. Thus, the objective of this work was to evaluate the use of substrates made with different amounts of dog fur and at different degradation times as a substrate in the cultivation of american lettuce. The experiment was implemented in a completely randomized design, in a $3 \times 3$ factorial scheme ( 3 compositions of substrates $x$ three times of decomposition of dog fur), with 10 repetitions per treatment, where each repetition consisted of a unit of $1 \mathrm{~kg}$ containing a plant of great lakes lettuce, totaling 90 experimental units. The composition of the substrates used was: substrate composed of $80 \%$ soil $+20 \%$ dog fur, $90 \%$ soil $+10 \%$ dog fur and control, containing $100 \%$ soil, and the degradation time was 90,120 and 150 days. The number of leaves, the diameter of the aerial part, the height of the aerial part, the fresh weight of the aerial part, the length of the root and the fresh weight of the root were evaluated. The use of substrates containing dog hair incorporated in different amounts and with different degradation times impaired $(p<0.05)$ the agronomic performance of lettuce, the fresh weight of the aerial part and the length and the fresh weight of the root. It is suggested that more research be conducted, based on a longer degradation time and/or the use of keratin hydrolysis techniques present in the dog fur, in order to enable the use of this residue as a biofertilizer.

Keywords: Lettuce cultivation; Waste management; Dog fur.

Topic: Experimentação Agrícola

Reviewed anonymously in the process of blind peer.
Received: 03/07/2021

Approved: 28/07/2021
Claudia Eliza Pinholi Mariano (iD)

Centro de Ensino Superior de Maringá, Brasil http://lattes.cnpq.br/1186725206741262 http://orcid.org/0000-0003-0456-2169 claudinha yasmin@hotmail.com

Márcia Aparecida Andreazzi it

Centro de Ensino Superior de Maringá, Brasil http://lattes.cnpq.br/0356767742666814

http://orcid.org/0000-0002-4663-3837 marcia.andreazzi@unicesumar.edu.br

Fabio Alexandre Moreschi Guastala Centro de Ensino Superior de Maringá, Brasil http://lattes.cnpq.br/1279995271685559 fabio.amguastala@gmail.com
Francielli Gasparotto (iD

Centro de Ensino Superior de Maringá, Brasil http://lattes.cnpq.br/2673470812353146 http://orcid.org/0000-0002-4038-7364 francielli.gasparotto@unicesumar.edu.br

José Maurício Gonçalves dos Santos (iD Centro de Ensino Superior de Maringá, Brasil http://lattes.cnpq.br/6226228129286305 http://orcid.org/0000-0002-2107-1137 jose.santos@unicesumar.edu.br

Andressa Araújo Machado do Nascimento (iD) Centro de Ensino Superior de Maringá, Brasil http://lattes.cnpq.br/7818455420043401 http://orcid.org/0000-0002-8980-0826 dessamachado@gmail.com
Vinicius Eduardo Gargaro Silva (iD Centro de Ensino Superior de Maringá, Brasil http://lattes.cnpq.br/5296843213119301 http://orcid.org/0000-0002-8153-3559 vinicius.gargaro@gmail.com

DOI: 10.6008/CBPC2179-6858.2021.007.0010

Referencing this:

MARIANO, C. E. P.; ANDREAZZI, M. A.; GUASTALA, F. A. M.; GASPAROTTO, F.; SANTOS, J. M. G.; NASCIMENTO, A. A. M.; SILVA, V. E. G.. Estudo sobre o uso de resíduos queratinosos como biofertilizante. Revista Ibero Americana de Ciências Ambientais, v.12, n.7, p.105-111, 2021. DOI: http://doi.org/10.6008/CBPC2179$\underline{6858.2021 .007 .0010}$ 


\section{INTRODUÇÃO}

O aumento na população de animais de estimação tem gerado a necessidade de maiores cuidados com alimentação, saúde e higiene destes animais (MAZON et al., 2017), por isso, o número de lojas de comércio e prestação de serviços para animais de estimação, denominadas pet shops (PEINADO et al., 2012) tem aumentado muito em várias regiões. Dentre os serviços ofertados por estas lojas, destaca-se os serviços de higiene, como a tosa, que promove a higienização e contribui com a beleza do animal. Contudo, em função da elevada população de pets, este procedimento resulta na geração de grande quantidade de pelos.

Os pelos são classificados como resíduos queratinosos e, assim como as penas, lã, cabelos, unhas, cascos, chifres, garras e bicos, são gerados em grande quantidade no planeta (SHAH et al., 2018) e se associam a graves problemas de poluição ambiental (ONIFADE et al., 1998).

Trabalhos têm demonstrado diferentes formas de destinação e uso destes resíduos a fim de reduzir seus impactos ambientais, como a biotransformação (NUMPAQUE et al., 2016), a compostagem (CHOIŃSKAPULIT et al., 2019), o uso na fabricação de rações para diferentes espécies animais (MORITZ et al., 2001; PANDEY et al., 2019) ou como biofertilizante em diferentes culturas (ZHELAZKOV, 2005; SUZUKI et al., 2006; ZHELJAZKOV et al., 2008b; SHAH et al., 2018).

Com relação ao uso como biofertilizante, Zheljazkov et al. (2008a) conduziram dois experimentos para avaliar o potencial biofertilizante de cabelos humanos para o cultivo de alface (Lactuca sativa) e absinto (Artemisia annua), que foram cultivados em substratos comerciais contendo resíduos de cabelos. Após o cultivo e colheita da alface e do absinto, os pesquisadores cultivaram, nos mesmos vasos da pesquisa anterior, papoula amarela (Glaucium flavum) e observaram que o uso de substratos contendo resíduos de cabelo não foram adequados como fonte única de nutrientes para o cultivo das plantas estudadas, já que eram de rápido crescimento, e afirmaram que, em função da estrutura queratinosa, estes resíduos necessitam de um tempo maior de degradação que resulte na liberação dos nutrientes para as plantas.

Entretanto, dando sequência à mesma linha de pesquisa, mas avaliando a lã como fonte de resíduo queratinoso, o mesmos pesquisadores cultivaram acelga suíça (Beta vulgaris L.) e manjericão (Ocimum basilicum L.) em substratos contendo diferentes quantidades de resíduos de lã, durante quatro colheitas para acelga e cinco para manjericão e observaram resultados positivos no crescimento dos vegetais, concluindo que a incorporação de resíduos de lã pode alterar as características do solo e ser fonte de nutrientes para as plantas (ZHELJAZKOV et al., 2009).

Desta forma, buscando contribuir com a sustentabilidade ambiental da Cadeia Produtiva dos Animais de Estimação ou Cadeia Pet, o objetivo desse trabalho foi avaliar o uso de substratos elaborados com diferentes quantidades de resíduos de pelos de cães e em diferentes tempos de degradação no cultivo de alface americana.

\section{METODOLOGIA}

O estudo foi conduzido nos meses de dezembro de 2019 a julho de 2020, em Maringá, Paraná, Brasil 
$\left(23^{\circ} 26^{\prime}, 51^{\circ} 56^{\prime} \mathrm{O}\right.$ e altitude de 545 metros).

O experimento foi implantado em um delineamento inteiramente casualizado (DIC), em esquema fatorial 3x3 (3 composições de substratos $x$ três tempos de degradação do pelo de cão), com 10 repetições por tratamento, onde cada repetição foi constituída por uma unidade de $1 \mathrm{~kg}$ contendo uma planta de alface americana cultivar Grandes Lagos, totalizando 90 unidades experimentais.

Os tratamentos experimentais foram: T1 - substrato composto por $80 \%$ de solo $+20 \%$ de pelo, $\mathrm{T} 2-$ substrato composto por $90 \%$ de solo $+10 \%$ de pelo e T3 - testemunha, substrato composto por $100 \%$ de solo, sendo T1, T2 e T3 com tempo de degradação de 90 dias; T4 - substrato composto por $80 \%$ de solo + $20 \%$ de pelo, $\mathrm{T} 5$ - substrato composto por $90 \%$ de solo $+10 \%$ de pelo e $\mathrm{T} 6$ - testemunha, substrato composto por $100 \%$ de solo, sendo T4, T5 e T6 com tempo de degradação de 120 dias, e T7 - substrato composto por $80 \%$ de solo $+20 \%$ de pelo, $\mathrm{T} 8$ - substrato composto por $90 \%$ de solo $+10 \%$ de pelo e T9 - testemunha, substrato composto por $100 \%$ de solo, sendo T7, T8 e T9 com tempo de degradação de 150 dias.

O solo foi coletado na fazenda escola da Universidade Cesumar/ Unicesumar. O resíduo queratinoso utilizado foi pelo de cachorro, obtido a partir de lojas de comércio e prestação de serviços para animais de estimação (pet shops), localizadas em Maringá/ PR. No total, 9kg de pelos foram picotados em um comprimento médio de $5 \mathrm{~mm}$, com auxílio de tesoura e incorporados ao solo nas proporções estabelecidas acima.

Para obtenção dos substratos de acordo com os tempos de degradação, os pelos, previamente picotados, foram incorporados ao solo, em recipientes plásticos de 30 litros, umedecidos e fechados, e mantidos em processo de degradação pelo período de 90, 120 e 150 dias antes da semeadura da alface. 0 preparo de cada substrato foi realizado em períodos diferentes, de modo a permitir que a semeadura de todas as amostras, ocorresse no mesmo momento.

Decorrido os períodos de degradação definidos para o estudo, as sementeiras foram confeccionadas com os substratos, empregando-se sacos plásticos de $1 \mathrm{~kg}$, próprios para mudas, nos quais foram adicionados os substratos de cultivo, de acordo com cada tratamento. A semeadura foi realizada manualmente, na profundidade de $1,5 \mathrm{~cm}$, utilizando-se 3 sementes de alface por amostra. As mudas foram colocadas em armação em madeira, próximas à superfície do solo, e protegidas por tela sombrite $50 \%$. A irrigação foi realizada diariamente ao longo do período de cultivo.

Para a avaliação do desempenho agronômico da cultura durante seu ciclo (55 dias), foram realizadas a contagem do número de folhas (NF), a medição do diâmetro da parte aérea (DPA) e da altura da parte aérea (APA) com auxílio de uma fita métrica $(\mathrm{cm})$, a cada sete dias.

Ao final do experimento, todas as plantas foram colhidas, lavadas, secas em papel toalha e foram avaliados os seguintes parâmetros: massa fresca da parte aérea (MFPA) - para tanto, as plantas de cada tratamento foram seccionadas à altura do colo, separando-se a parte aérea da raiz e, em seguida, foi realizada a avaliação da massa da parte aérea ( $\mathrm{g}$ ) empregando-se uma balança de precisão; a determinação do comprimento de raiz (CR) foi realizada após a separação das raízes da parte aérea, empregando-se uma fita métrica $(\mathrm{cm})$ e a análise da massa fresca da raiz (MFR) foi obtida por meio da pesagem das raízes (g) com 
auxílio de uma balança de precisão.

Os resultados do número de folhas, diâmetro da parte aérea e altura da parte aérea foram submetidos à análise de variância e as médias comparadas pelo teste de Scott - Knott a 5\% de significância. Os dados sobre massa fresca da parte aérea, massa fresca da raiz e comprimento de raiz foram tabulados e as análises estatísticas das variáveis foram feitas empregando GLM Procedure, do programa computacional estatístico SAS, versão 8.01.

\section{RESULTADOS E DISCUSSÃO}

Os dados desta pesquisa mostraram que a incorporação de 20 e $10 \%$ de pelo de cachorro ao solo, com tempo de degradação de 90 dias comprometeu $(p<0,05)$ o número de folhas e o diâmetro da parte aérea da alface americana. Infelizmente, aos 120 dias, não houve germinação e crescimento de nenhuma alface em substrato contendo $20 \%$ de pelo, mas observou-se que o tratamento contendo $10 \%$ foi inferior $(p<0,05)$ ao grupo testemunha. Contudo, após 150 dias de degradação, não foram observadas diferenças quanto ao diâmetro e altura da parte aérea entre os tratamentos $(p>0,05)$, apesar do menor número de folhas, sinalizando que um maior tempo de degradação pode gerar resultados mais promissores (Tabela 1).

Tabela 1: Média do número de folhas (NF), diâmetro da parte aérea (DPA) e altura da parte aérea (APA) de alface americana variedade Grandes Lagos, cultivada em substrato composto por diferentes quantidades de pelo de cachorro, submetidos a diferentes tempos de degradação ( $\mathrm{n}: 90)$.

\begin{tabular}{llll}
\hline \multirow{2}{*}{ Tratamento } & NF & DPA $(\mathbf{c m})$ & APA $(\mathbf{c m})$ \\
\cline { 2 - 4 } & $\mathbf{9 0}$ dias & & $11,23 \mathrm{a}$ \\
T1 & $12,7 \mathrm{~b}$ & $15,50 \mathrm{~b}$ & $10,05 \mathrm{a}$ \\
T3 & $12,8 \mathrm{~b}$ & $15,35 \mathrm{~b}$ & $13,05 \mathrm{a}$ \\
\hline & $19,7 \mathrm{a}$ & $27,05 \mathrm{a}$ & - \\
\hline T4 & $\mathbf{1 2 0}$ dias & & $9,96 \mathrm{~b}$ \\
T5 & - & & $14,0 \mathrm{a}$ \\
T6 & $14,9 \mathrm{~b}$ & $20,80 \mathrm{~b}$ & \\
\hline & $19,8 \mathrm{a}$ & $26,40 \mathrm{a}$ & $12,47 \mathrm{a}$ \\
\hline T7 & $\mathbf{1 5 0}$ dias & & $14,65 \mathrm{a}$ \\
T8 & $16,1 \mathrm{~b}$ & $28,50 \mathrm{a}$ & $13,73 \mathrm{a}$ \\
\hline
\end{tabular}

Tratamentos: T1, T4 e T7 - substratos compostos por $80 \%$ de solo + 20\% de pelo; T2, T4 e T8 - substratos compostos por $90 \%$ de solo $+10 \%$ de pelo; T3, T6 e T9 - testemunha, composto por $100 \%$ de solo. Médias seguidas de letras diferentes na mesma coluna diferem entre si pelo teste de Scott Knott (5\%).

A incorporação de 20 ou $10 \%$ de pelo de cachorro ao substrato, submetido aos tempos de degradação de 90, 120 e 150 dias reduziu as médias da massa fresca da parte aérea, massa fresca da raiz e comprimento de raiz $(p<0,05)$ (Tabela 2$)$. Contudo, ressaltamos que as plantas cultivadas no substrato degradado por 150 dias apresentaram menores diferenças em relação ao grupo testemunha, assim, apontamos novamente que, um maior tempo de degradação parece ser primordial para o melhor desenvolvimento das plantas.

Considerando-se a média geral da massa fresca da parte aérea, massa fresca da raiz e do comprimento de raiz em função da quantidade de pelo de cão incorporado (Tabela 3) e tempo de degradação (Tabela 4), observou-se que incorporação do pelo prejudicou a maioria dos parâmetros observados sobre o desempenho da alface, independentemente da quantidade incorporada e do tempo de degradação $(p<0,05)$. 
Tabela 2: Média da massa fresca da parte aérea (MFPA), massa fresca da raiz (MFR) e do comprimento de raiz (CR) de alface americana Grandes Lagos, cultivada em substrato composto por diferentes quantidades de pelo de cachorro, submetidos a diferentes tempos de degradação ( $\mathrm{n}: 90)$.

\begin{tabular}{|c|c|c|c|}
\hline \multirow[t]{2}{*}{ Tratamento } & MFPA (g) & MFR (g) & $\mathrm{CR}(\mathrm{cm})$ \\
\hline & \multicolumn{3}{|c|}{ 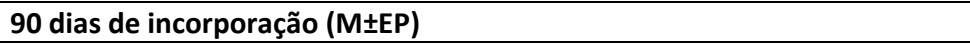 } \\
\hline T1 & $0,07 \pm 0,22$ & $0,33 \pm 1,04$ & $1,80 \pm 2,55$ \\
\hline T2 & $0,20 \pm 0,42$ & $0,14 \pm 0,29$ & $1,40 \pm 2,98$ \\
\hline \multirow[t]{2}{*}{ T3 } & $1,07 \pm 1,30$ & $2,17 \pm 2,26$ & $9,10 \pm 8,00$ \\
\hline & \multicolumn{3}{|c|}{120 dias de incorporação (M士EP) } \\
\hline T4 & 0,00 & 0,00 & 0,00 \\
\hline T5 & $0,18 \pm 0,57$ & $0,30 \pm 0,95$ & $1,70 \pm 5,37$ \\
\hline \multirow[t]{2}{*}{ T6 } & $2,25 \pm 1,35$ & $5,15 \pm 3,26$ & $10,25 \pm 6,05$ \\
\hline & \multicolumn{3}{|c|}{150 dias de incorporação (M士EP) } \\
\hline T7 & $1,04 \pm 1,38$ & $1,61 \pm 2,23$ & $6,50 \pm 8,60$ \\
\hline T8 & $1,11 \pm 1,94$ & $1,60 \pm 2,67$ & $5,40 \pm 8,81$ \\
\hline T9 & $2,08 \pm 1,88$ & $4,44 \pm 3,75$ & $9,90 \pm 8,18$ \\
\hline Valor de $p$ & 0,0006 & 0,0001 & 0,0315 \\
\hline
\end{tabular}

Tratamentos: T1, T4 e T7 - substratos compostos por $80 \%$ de solo + 20\% de pelo; T2, T5 e T8 - substrato composto por $90 \%$ de solo $+10 \%$ de pelo; T3, T6 e T9 - testemunha, composto por $100 \%$ de solo. M \pm EP: média e mais ou menos erro padrão da média.

Tabela 3: Média geral da massa fresca da parte aérea (MFPA), massa fresca da raiz (MFR) e do comprimento de raiz (CR) de alface americana Grandes Lagos cultivada em substrato contendo diferentes quantidades de pelos de cachorro (n:90).

\begin{tabular}{lllll}
\hline Variável & \multicolumn{4}{l}{ Quantidade de pelo de cão incorporada (\%) } \\
\cline { 2 - 5 } & $\mathbf{2 0}$ & $\mathbf{1 0}$ & $\mathbf{0}$ & Valor de $\mathbf{p}$ \\
\hline MFPA (g) & 1,07 & 0,50 & 1,45 & 0,0371 \\
MFR (g) & 2,38 & 0,68 & 2,98 & 0,0049 \\
CR (cm) & 5,20 & 2,83 & 10,62 & 0,0116 \\
\hline
\end{tabular}

Tabela 4: Média geral da massa fresca da parte aérea (MFPA), massa fresca da raiz (MFR) e do comprimento de raiz (CR) de alface americana Grandes Lagos cultivada em substrato contendo diferentes quantidades de pelos de cachorro e diferentes tempos de incorporação dos pelos ( $\mathrm{n}: 90)$.

\begin{tabular}{lllll}
\hline Variável & \multicolumn{3}{l}{ Tempo de degradação (dias) } \\
\cline { 2 - 5 } & $\mathbf{9 0}$ & $\mathbf{1 2 0}$ & $\mathbf{1 5 0}$ & Valor de $\mathbf{p}$ \\
\hline MFPA (g) & 0,45 & 1,21 & 1,41 & 0,0270 \\
MFR (g) & 0,88 & 2,72 & 2,55 & 0,0290 \\
CR (cm) & 5,66 & 8,97 & 7,27 & 0,5500 \\
\hline
\end{tabular}

Os achados neste estudo se assemelham, parcialmente, aos reportados por Zheljazkov et al. (2008), que avaliaram o uso de cabelo humano como biofertilizante em experimentos conduzidos com alface (Lactuca sativa) e absinto (Artemisia annua). Os autores empregaram níveis de 0\%, 2,5\%, 5\% e 10\% de resíduos de cabelos adicionados a substratos comerciais e, após o cultivo e colheita da alface e do absinto, cultivaram, nos mesmos vasos, papoula amarela (Glaucium flavum). Ao final dos dois experimentos, os autores não aconselharam o uso dos substratos testados para plantas de rápido crescimento, justificando que, em função da estrutura da queratina, a principal proteína presente no fio do cabelo, o tempo de degradação deveria ser maior a fim de permitir a liberação dos nutrientes para as plantas. De fato, Onifade et al. (1998) afirmou que a resistência à degradação dos cabelos e pelos é consequência do empacotamento das cadeias de $\alpha$-queratina.

Entretanto, dando sequência ao estudo, os mesmos pesquisadores (ZHELJAKOV et al., 2009) cultivaram acelga suíça (Beta vulgaris L.) e manjericão (Ocimum basilicum L.) em substratos contendo resíduos de lã nas quantidades de 0,20,40, 80 e 120g de lã por vaso, durante quatro colheitas para acelga e cinco para manjericão e observaram resultados positivos quanto à taxa de crescimento dos vegetais. Assim, 
os autores concluíram que a incorporação de resíduos de lã pode ser benéfica para os vegetais em função das alterações nas características do solo e do fornecimento de nutrientes para as plantas.

Apesar dos resultados deste estudo não terem sido satisfatórios, apontamos que a Política Nacional de Resíduos Sólidos (PNRS), instituída no Brasil pela Lei $\mathrm{N}^{\circ} 12.305$, aponta que a gestão integrada e o gerenciamento dos resíduos sólidos são de responsabilidade dos geradores e do poder público (BRASIL, 2010). Assim, observa-se que os pet shops são responsáveis pela gestão correta dos pelos gerados pela tosa e, por isso, pesquisas devem ser conduzidas a fim de contribuir com a resolução deste problema relacionado à Cadeia Produtiva dos Animais de Estimação ou Cadeia Pet.

Enfatizamos que essa cadeia é um segmento do agronegócio relacionado com o desenvolvimento das atividades de criação, indústrias e comercialização de animais de estimação e de produtos relacionados (BRASIL, 2017), que tem apresentado notável crescimento no país (MAZON et al., 2017) e, além disso, os resíduos queratinosos se constituem no terceiro polímero mais abundante na natureza, depois da celulose e da quitina, justificando a necessidade de mais pesquisas sobre o assunto.

Somado a estes fatos, reportamos que a preocupação com os resíduos, de qualquer natureza, segue ao encontro dos Objetivos do Desenvolvimento Sustentável (ODS), que compõem uma agenda global e envolvem ações para acabar com a pobreza, promover a prosperidade e o bem-estar para todos, enfrentar as mudanças climáticas e proteger o meio ambiente (UNESCO, 2015), sobretudo com relação à gestão de resíduos de formas ambientalmente corretas.

Por isso, recomenda-se que mais estudos sejam realizados, a fim de propor protocolos mais satisfatórios para o uso de pelos de cachorro como biofertilizante. Como possibilidade, aventamos um maior tempo de degradação do resíduo ou sua hidrólise prévia, conforme preconizado por alguns pesquisadores (ARRUDA, 2010; DHAKAL et al., 2018; SUREK et al., 2018).

\section{CONCLUSÕES}

O uso de substratos contendo pelos de cachorros incorporados em diferentes quantidades e com tempos diferentes de degradação prejudicou o desempenho e a produção da alface americana Grandes Lagos. Baseados na importância da busca por destinações ambientalmente corretas para os resíduos queratinosos, como os pelos de cachorro, sugere-se que mais pesquisas sejam conduzidas, pautadas em maior tempo de degradação e/ou o uso de técnicas de hidrólise da queratina presente no pelo, a fim de viabilizar o uso desse resíduo como biofertilizante.

\section{REFERÊNCIAS}

ARRUDA, M. N.. Extração, caracterização e modificação química da queratina extraída das penas de frango. Dissertação (Mestrado em Tecnologia Químico-

Farmacêutica) - Universidade de São Paulo, São Paulo, 2010

BRASIL. Lei n. 12.305 de 02 de agosto de 2010. Dispõe sobre a Política Nacional de Resíduos Sólidos e dá outras providências. Brasília: DOU, 2010.
BRASIL. Ministério da Agricultura, Pecuária e Abastecimento. Agenda Estratégica Pet Brasil. Brasília: MAPA, 2017.

CHOIŃSKA-PULIT, A; ŁABA, W.; RODZIEWICZ, A... Enhancement of pig bristles waste bioconversion by inoculum of keratinolytic bacteria during composting. Waste management, Napoli, v.84, p.269-276, 2019.

DOI: http://doi.org/10.1016/j.wasman.2018.11.052 
DHAKAL, D.; KOOMSAP, P.; LAMICHHANE, A.; SADIQ, M. B.; ANAL, A. K.. Optimization of collagen extraction from chicken feet by papain hydrolysis and synthesis of chicken feet collagen based biopolymeric fibres. Food bioscience, Jiangsu, v.23, p.23-30, 2018. DOI: http://doi.org/10.1016/j.fbio.2018.03.003

MAZON, M. S.; MOURA, W. G.. Cachorros e humanos: Mercado de rações pet em perspectiva sociológica. Civitas, Revista de Ciências Sociais, Porto Alegre, v.17, n.1, p.138158, 2017. DOI: http://doi.org/10.15448/19847289.2017.1.25292

MORITZ, J. S.; LATSHAW, J. D.. Indicators of nutritional value of hydrolyzed feather meal. Poultry Science, Champaign, v.80, n.1, p.79-86, 2001

NUMPAQUE, R.; VITERI, S.. Biotransformación del pelo residual de curtiembres. Revista de Ciências Agrárias, San Juan de Pasto, v.33, n.2, p.95-105, 2016. DoI: http://dx.doi.org/10.22267/rcia.163302.56

ONIFADE, A. A.; AL-SANE, A. A.; AL-MUSALLAM, A. A; ALZARBAN, S.. A review: potentials for biotechnological applications of keratin-degrading microorganisms and their enzymes for nutritional improvement of feathers and other keratins as livestock feed resources. Bioresource technology, Lucknow, v.66, n.1, p.1-11, 1998. DOI: http://doi.org/10.1016/S0960-8524(98)00033-9

UNESCO. Organização das Nações Unidas para a Educação a Ciência e a Cultura. Agenda de Desenvolvimento pós-2015 UNESCO e os Objetivos de Desenvolvimento Sustentável. UNESCO, 2015

PEINADO, J.; FERNANDES, B. H. R.. Estratégia, competências e desempenho em empresas de pet shop: evidências de um levantamento em Curitiba. Revista de Administração, São Paulo, v.47, n.4, p.609-623, 2012. DOI: http://doi.org/10.5700/rausp1062
SHAH, A.; TYAGI, S.; BHARAGAVA, R. N.; BELHAJ, D.; KUMAR, K.; SAXENA, G.; SARATALE, G. D.; MULLA, S. I.. Keratin Production and Its Applications: Current and Future Perspective. In: Keratin as a Protein Biopolymer. Springer: Cham, 2018. p.19-34.

SUREK, D.; BEDENDO, G. C.; KRABBE, E. L.. Otimização da hidrólise de penas de frango com utilização de mamão. In: CONGRESSO BRASILEIRO DE ENGENHARIA AGRÍCOLA, 47. Anais. Brasília: SBEA, 2018

SUZUKI, Y.; TSUJIMOTO, Y.; MATSUI, H.; WATANABE, K. Decomposition of extremely hard-to-degrade animal proteins by thermophilic bacteria. Journal of Bioscience and bioengineering, Fukuoka, v.102, n.2, p.73-81, 2006. DOI: http://doi.org/10.1263/jbb.102.73

ZHELJAZKOV, V. D.. Assessment of wool-waste and hair waste as soil amend- ment and nutrient source. Journal of Environmental Quality, v.34, p.2310-2317, 2005. DOI: http://doi.org/10.2134/jeq2004.0332

ZHELJAZKOV, V. D.; SILVA, J. L.; PATEL, M.; STOJANOVIC, J.; LU, Y.; KIM, T.; HORGAN, T.. Human Hair as a Nutrient Source for Horticultural Crops. HortTechnology, v.18, p.549745, 2008a. DOI: http://doi.org/10.21273/HORTTECH.18.4.592

ZHELJAZKOV, V. D.; STRATTON, G. W.; STURZ, T..

Uncomposted wool and hair-wastes as soil amendments for high-value crops. Agronomy Journal, v.100, n.6, 2008b. DOI: http://doi.org/10.2134/agronj2007.0214

ZHELJAZKOV, V. D.; STRATTON, G. W.; PINCOCK, J.; BUTLER, S.; JELIAZKOVA, E. A.; NEDKOV, N. K.; GERARD, P. D.. Woolwaste as organic nutrient source for container-grown plants. Waste Management, Napoli, v.29, n.7, p.2160-2164, 2009. DOI: http://doi.org/10.1016/j.wasman.2009.03.009

A CBPC - Companhia Brasileira de Produção Científica (CNPJ: 11.221.422/0001-03) detém os direitos materiais desta publicação. Os direitos referem-se à publicação do trabalho em qualquer parte do mundo, incluindo os direitos às renovações, expansões e disseminações da contribuição, bem como outros direitos subsidiários. Todos os trabalhos publicados eletronicamente poderão posteriormente ser publicados em coletâneas impressas sob coordenação da Sustenere Publishing, da Companhia Brasileira de Produção Científica e seus parceiros autorizados. Os (as) autores (as) preservam os direitos autorais, mas não têm permissão para a publicação da contribuição em outro meio, impresso ou digital, em português ou em tradução. 